\title{
Synthesis and characterization of single-source molecular precursors for the preparation of metal chalcogenides
}

\author{
VIMAL K JAIN \\ Chemistry Division, Bhabha Atomic Research Centre, Mumbai 400085 \\ e-mail: jainvk@barc.gov.in
}

\begin{abstract}
Metal chalcogenides constitute an important family of functional materials. Subtle changes in shape, size and phase of these materials result in variations in physical properties (e.g. electronic and optical), which can be exploited for various technological applications. Several strategies have evolved recently for controlling shape, size and phase of these materials. This work discusses design and synthesis of single-source molecular precursors for the preparation of metal chalcogenides both in bulk and nano-size regime. Precursors for palladium chalcogenides, indium sulphides and II-VI materials are presented. Synthesis of a variety of palladium(II)/platinum(II) complexes with internally functionalised chalcogenolate ligands, selenocarboxylates; gallium and indium dithiolate complexes and zinc/cadmium/ mercury complexes with $\mathrm{N}, \mathrm{N}^{\prime}$-dimethylaminoalkylselenolate ligands and their characterization by NMR and X-ray crystallography are also discussed. Data on thermal behaviour of a few representative complexes, $\left[\mathrm{Pd}(\mathrm{SeCOAr})_{2}\left(\mathrm{PR}_{3}\right)_{2}\right],\left[\mathrm{PdCl}\left(\mathrm{E}^{\cap} \mathrm{N}\right)\left(\mathrm{PR}_{3}\right)\right],\left[\operatorname{InMe}_{2}\left(\mathrm{~S}^{\cap} \mathrm{S}\right)\right],\left[\operatorname{In}\left(\mathrm{S}^{\cap} \mathrm{S}\right)_{3}\right]$ and $\left[\mathrm{M}\left(\mathrm{E}\left(\mathrm{CH}_{2}\right)_{n} \mathrm{NMe}_{2}\right)_{2}\right]$ $(\mathrm{M}=\mathrm{Zn}, \mathrm{Cd}, \mathrm{Hg} ; n=2$ or 3$)$ are presented.
\end{abstract}

Keywords. Palladium; platinum; indium; chalcogenolates; metal chalcogenides; nanoparticles.

\section{Introduction}

Chemistry of metal chalcogenolates has been one of the active areas of research for several years and is dominated by metal thiolates. Their potential application as single-source molecular precursors for metal chalcogenides has further accelerated work on these complexes. Metal chalcogenolates, in general, are isolated as non-volatile, insoluble or sparingly soluble oligomeric species, therefore limiting their utility as molecular precursors.<smiles>Fc1ccccn1</smiles>

(1)

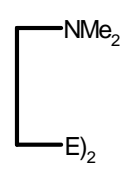

(2)

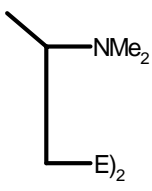

(3)

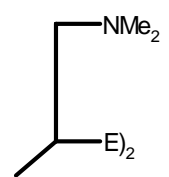

(4)

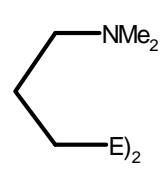

(5)
$\mathrm{E}=\mathrm{O}, \mathrm{S}, \mathrm{Se}, \mathrm{Te}$ ever, synthetic challenges to prepare these ligands in high yields without carbon contamination in some pyrolysed derivatives led us to conceive yet another family of internally functionalised ligands -i.e. aminoalkylchalcogenolates, $\quad \mathrm{R}_{2} \mathrm{~N}\left(\mathrm{CR}^{\prime}\right)_{n} \mathrm{E}^{-} \quad(\mathbf{2}-\mathbf{5})$. While the chemistry of mercapto alkylamines is reported by other workers ${ }^{5}$, heavier analogues containing Se and Te have been developed at $\mathrm{BARC}^{6-14}$.

\section{Results and discussion}

$\mathrm{N}, \mathrm{N}$-Dimethylaminoalkylchalcogenolato ligands were prepared by the reaction of $\mathrm{Na}_{2} \mathrm{E}_{2}(\mathrm{E}=\mathrm{S}, \mathrm{Se}, \mathrm{Te})$ with an appropriate alkylchloride. The reaction of $\mathrm{Me}_{2} \mathrm{NCH}_{2}$ $\mathrm{CHMeCl}$ results in isomerization giving a mixture of $\left(\mathrm{Me}_{2} \mathrm{NCH}(\mathrm{Me}) \mathrm{CH}_{2} \mathrm{E}\right)_{2}(3)$ and $\left(\mathrm{Me}_{2} \mathrm{NCH}_{2} \mathrm{CH}(\mathrm{Me}) \mathrm{E}\right)_{2}$ (4), relative ratio of which depends on the nucleophilic character of the chalcogen atom (reaction with $\mathrm{NaSH}$ gave 3 ( $\mathrm{E}=\mathrm{S}$ ) exclusively). Thus the formation of $\mathbf{4}$ decreases on going from $\mathrm{S}$ to Se through $\mathrm{Te}$ (ratio of 3 and 4 is $1: 2(\mathrm{~S}) ; 1: 1(\mathrm{Se})$ and $5: 1(\mathrm{Te})$ ). The ${ }^{77} \mathrm{Se}$ NMR spectrum shows eight lines (figure 1) which are assigned to $R R / S S$ and meso forms of $\mathbf{3}$ and 4. The intra-molecular interactions between $\mathrm{Se}$ and $\mathrm{N}$ may lead to magnetic non-equivalence of Se atoms in each molecule. 
Several reactions of N,N-dimethylaminoalkylchalocogenolates with palladium and platinum complexes have been carried out, some of which are discussed here. The structure and stereochemistry of these complexes are generally influenced by the number of carbon atoms between $\mathrm{E}$ and $\mathrm{N}$ and the nature of the chalcogen atom.

The reaction of $\mathrm{Na}_{2} \mathrm{PdCl}_{4} / \mathrm{K}_{2} \mathrm{PtCl}_{4}$ with $\mathrm{NaE}^{\cap} \mathrm{N}$, prepared by sodium borohydride reduction of $\mathbf{2 - 5}$, yields homoleptic chalcogenolates of composition $\left[\mathrm{M}\left(\mathrm{E}^{\cap} \mathrm{N}\right)_{2}\right]_{n}$ (scheme 1). The FAB mass spectra and $\mathrm{X}$-ray structure revealed hexameric structure. The molecule $\left(\mathrm{E}^{\cap} \mathrm{N}=\mathrm{SeCH}_{2} \mathrm{CH}_{2} \mathrm{CH}_{2} \mathrm{NMe}_{2}\right)$ has a hexagonal cyclo- $\left[\mathrm{PdSe}_{2}\right]_{6}$ centre in which two palladium atoms are bridged by two selenolate Se atoms while the tertiary amine functions remain uncoordinated.

Treatment of $\mathrm{Na}_{2} \mathrm{PdCl}_{4} / \mathrm{K}_{2} \mathrm{PtCl}_{4}$ with $\mathbf{2 - 5}$ in methanol yields sparingly soluble complexes of empirical composition $\left[\mathrm{MCl}\left(\mathrm{E}^{\cap} \mathrm{N}\right)\right]_{n}$. The trimeric structure $^{7}$ is formed with the ligands (2-4) where $\mathrm{E}$ and $\mathrm{N}$ are separated by two carbon atoms as shown by FAB mass $(m / z=879)$ and $\mathrm{X}$-ray structural analysis of $\left[\mathrm{PdCl}\left(\mathrm{SeCH}_{2} \mathrm{CH}_{2} \mathrm{NMe}_{2}\right)\right]_{3}$. However, the palla-

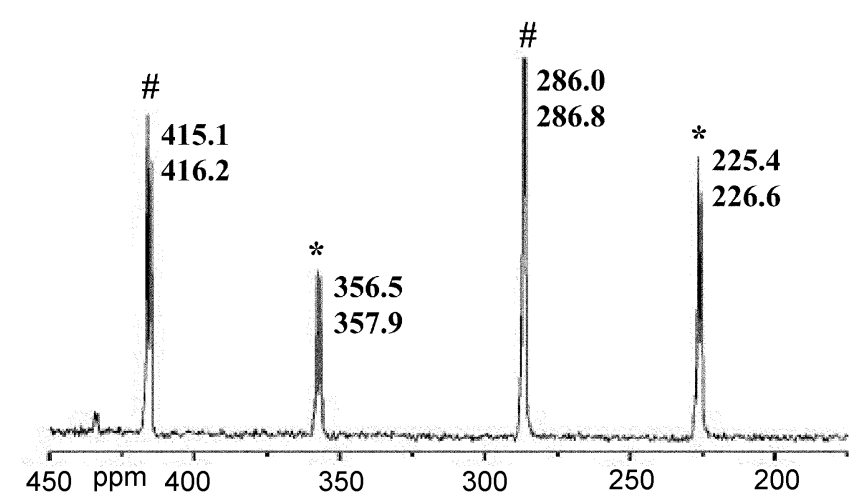

Figure 1. ${ }^{77} \mathrm{Se}\left\{{ }^{1} \mathrm{H}\right\}$ NMR spectrum of a mixture of $(3) *$ and (4)\#, E = Se.

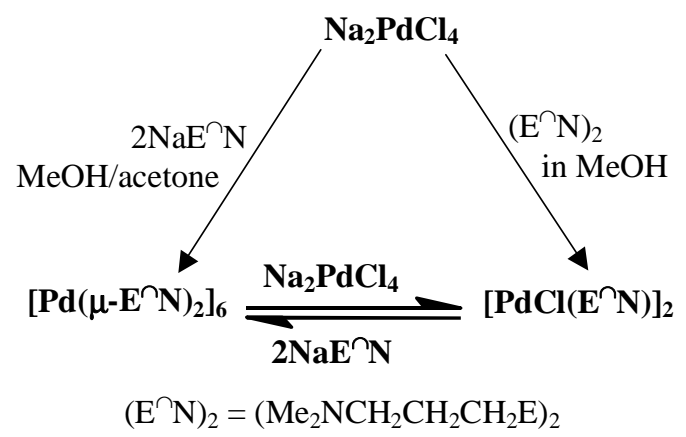

Scheme 1.

dium complexes derived from $\mathbf{5} \quad\left(\mathrm{Me}_{2} \mathrm{NCH}_{2}\right.$ $\mathrm{CH}_{2} \mathrm{CH}_{2} \mathrm{E}^{-}$) adopt a dimeric structure as shown by FAB mass spectrum $(m / z=614)$ and X-ray crystallography. ${ }^{11}$ The hexanuclear complex ${ }^{12}$ reacts readily with $\mathrm{Na}_{2} \mathrm{PdCl}_{4}$ or $\mathrm{Pd}(\mathrm{OAc})_{2}$ to afford binuclear complexes $\quad\left[\mathrm{PdX}\left(\mathrm{ECH}_{2} \mathrm{CH}_{2} \mathrm{CH}_{2} \mathrm{NMe}_{2}\right)\right]_{2} \quad(\mathrm{X}=\mathrm{Cl}$, $\mathrm{OAc}$ ) in which two chelating chalcogenolate ligands bridge two palladium atoms. Interconversion of dimeric to hexameric species is quite facile (scheme 1).

Treatment of $\left[\mathrm{M}_{2} \mathrm{Cl}_{2}(\mu-\mathrm{Cl})_{2}\left(\mathrm{PR}_{3}\right)_{2}\right]$ with two equivalents of $\mathrm{NaE}^{\cap} \mathrm{N}(\mathbf{2}-\mathbf{4})$ prepared by reductive cleavage of the $\mathrm{E}^{\cap} \mathrm{E}$ bond in $\left(\mathrm{N}^{\cap} \mathrm{E}\right)_{2}$ with $\mathrm{NaBH}_{4}$ in methanol gave monomeric $\left[\mathrm{MCl}\left(\mathrm{ECH}_{2} \mathrm{CH}_{2} \mathrm{NMe}_{2}\right)\right.$ $\left.\left(\mathrm{PR}_{3}\right)\right]$. The latter can also be obtained by the reaction of $\left[\mathrm{MCl}\left(\mathrm{E}^{\cap} \mathrm{N}\right)\right]_{n}$ with phosphine (scheme 2). Complexes containing $\mathrm{Me}_{2} \mathrm{NCH}_{2} \mathrm{CH}_{2} \mathrm{~S}^{-}$and alkyl phosphines, dimeric species containing thiolate bridges are also formed in small concentration. Stereochemistry of these complexes has been deduced by NMR $\left({ }^{1} \mathrm{H},{ }^{31} \mathrm{P},{ }^{77} \mathrm{Se},{ }^{195} \mathrm{Pt}\right)$ spectroscopy and X-ray crystallography. The ${ }^{77}$ Se NMR spectra display a doublet due to phosphorus coupling $\left({ }^{1} \mathrm{~J}(\mathrm{Pt}-\mathrm{Se})=\sim 130 \mathrm{~Hz}\right)$. The ${ }^{195} \mathrm{Pt}$ NMR spectra show a doublet in the region $\delta-4100$ to $-4425 \mathrm{ppm}$, where the shielding of the signal increases with increasing size of the chalcogen atom $(\mathrm{S}<\mathrm{Se}<\mathrm{Te})$. The ${ }^{31} \mathrm{P},{ }^{77} \mathrm{Se}$ and ${ }^{195} \mathrm{Pt}$ NMR spectra of complexes derived from $\mathbf{3}$ and $\mathbf{4}$ display two sets of resonances each attributed to complexes containing $\mathbf{3}$ and $\mathbf{4}$ ligand moeities. For $R$ and $S$ forms of each stereo-isomer one set of resonances is observed. The coordination environment around the metal centre is approximately square planar with the atoms $\mathrm{P}, \mathrm{Cl}, \mathrm{N}$ and $\mathrm{E}$ defining the coordination sphere. The neutral donor ( $\mathrm{P}$ and $\mathrm{N})$ atoms occupy trans positions. The five-membered chelate ring exhibits a twist conformation which combined with the presence of the methyl group substituents gives rise to two conformations, I and II, with different configurations at the asymmetric carbon ( $R$ for $\mathbf{I}$ and $S$ for II). Complexes with both isomeric ligands 3 and $4(\mathrm{E}=\mathrm{Se})$ co-crystallize in $\left[\mathrm{PdCl}\left(\mathrm{Se}^{\cap} \mathrm{N}\right)\left(\mathrm{PMePh}_{2}\right)\right]$ and the structure shows disorder according to conforations I and II.

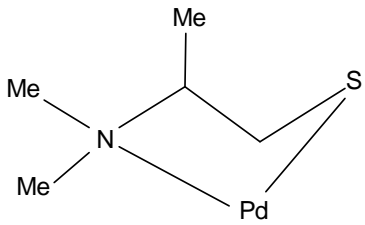

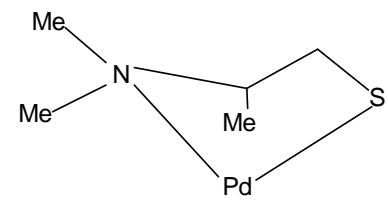

II 
The above reaction appears to proceed via a binuclear intermediate, $\left[\mathrm{M}_{2} \mathrm{Cl}_{3}\left(\mathrm{E}^{\cap} \mathrm{N}\right)\left(\mathrm{PR}_{3}\right)_{2}\right]$. Several such complexes have been isolated and characterized by NMR spectroscopy and X-ray crystallography. The ${ }^{31} \mathrm{P}$ and ${ }^{195} \mathrm{Pt}$ NMR spectra show two separate resonances as expected. The two square planar metal atoms are held together by a single chalcogenolate bridge.

The reaction of $\mathrm{PtCl}_{2}\left(\mathrm{P}^{\cap} \mathrm{P}\right)\left(\mathrm{P}^{\cap} \mathrm{P}=\right.$ dppm, dppe, or dppp) with two equivalents of $\mathrm{NaSeCH}_{2} \mathrm{CH}_{2} \mathrm{NMe}_{2}$ affords $c i s-\left[\mathrm{Pt}\left(\mathrm{SeCH}_{2} \mathrm{CH}_{2} \mathrm{NMe}_{2}\right)_{2}\left(\mathrm{P}^{\cap} \mathrm{P}\right)\right]$, but similar reaction with one equivalent of $\mathrm{NaSeCH}_{2} \mathrm{CH}_{2} \mathrm{NMe}_{2}$ in the presence of $\mathrm{NaBH}_{4}$ yields cationic binuclear complexes $\quad\left[\mathrm{Pt}_{2}\left(\mathrm{SeCH}_{2} \mathrm{CH}_{2} \mathrm{NMe}_{2}\right)_{2}\left(\mathrm{P}^{\cap} \mathrm{P}\right)_{2}\right]\left[\mathrm{BPh}_{4}\right]_{2}$ (scheme 3). These complexes have been characterized by ${ }^{31} \mathrm{P},{ }^{77} \mathrm{Se}$ and ${ }^{195} \mathrm{Pt}$ NMR spectroscopy.

Thermal behaviour of some of the palladium thiolate and selenolate complexes has been studied by thermogravimetric analysis. These complexes in general undergo a two-step decomposition leading to the formation of $\mathrm{Pd}_{4} \mathrm{~S}$ and $\mathrm{Pd}_{17} \mathrm{Se}_{15}$ as characterized by XRD and EDAX. Scanning electron micrographs of $\mathrm{Pd}_{17} \mathrm{Se}_{15}$ taken at different resolutions show large aggregates of microcrystals.

Most of the complexes are promising molecular precursors for the preparation of metal chacogenides, but their high decomposition temperature (above $300^{\circ} \mathrm{C}$ ) may be disadvantageous. Seleno and telluro carbocylic acids are unstable molecules and their metal complexes may provide a route for low tem-
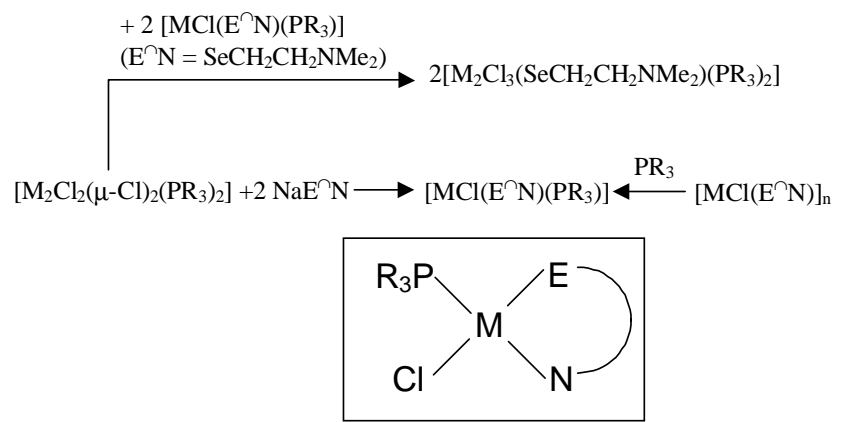

Scheme 2.

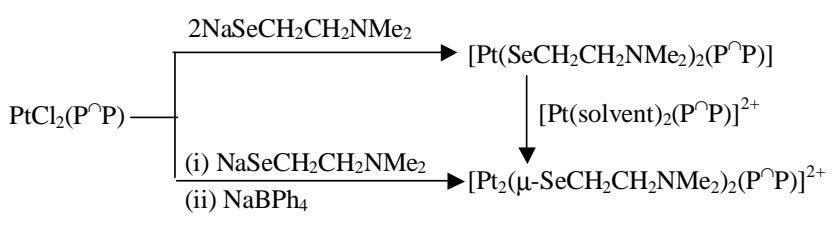

Scheme 3. perature synthesis of metal selenides and tellurides. Thus we prepared selenocarboxylates of palladium and platinum, $\left[\mathrm{M}(\mathrm{SeCOAr})_{2}\left(\mathrm{PR}_{3}\right)_{2}\right]$ (scheme 4). These complexes were characterized by IR, NMR and Xray crystallography. ${ }^{15}$ These complexes are monomeric. Like other mononuclear chalcogenolate complexes, we thought to use them for the preparation of bi-nuclear complexes. Surprisingly, a selenido-bridged trinuclear complexs is formed by unprecedented cleavage of $\mathrm{C}-\mathrm{Se}$ bond $^{16}$. The mononuclear complexes undergo a single step decomposition to yield $\mathrm{Pd}_{17} \mathrm{Se}_{15}$. When pyrolysis is carried out in TBP (tributyl phosphate) at $200^{\circ} \mathrm{C}$, nanoparticles of $\mathrm{Pd}_{17} \mathrm{Se}_{15}$ are obtained.

The III-VI semiconductors are potential materials for opto-electronic, and photovoltaic devices and also find applications as passivating layers for IIIVI devices. Among III-VI materials, $\beta-\operatorname{In}_{2} \mathrm{~S}_{3}$ is a front runner. Thus, to develop molecular precursors for III-VI we have explored chemistry of gallium and indium dithiolates. Thus several classical and organometallic complexes of gallium and indium with a variety of dithiolate ligands such as dialkyldithiophates, dithiocarbamates, xanthates and dithiocarboxylates, have been isolated (scheme 5) and characterized by IR, mass and NMR spectroscopy and X-ray crystallography. ${ }^{17-25}$ The following characteristic patterns are quite evident from their NMR spectra: (a) The methyl-metal resonance in ${ }^{1} \mathrm{H}$ and ${ }^{13} \mathrm{C}$ NMR spectra showed deshielding on replacing a methyl group on metal ( $\mathrm{Ga}$ or In) by a dithio ligand and followed the trend $\mathrm{Me}_{3} \mathrm{M} \cdot \mathrm{OEt}_{2}>\mathrm{Me}_{2} \mathrm{M}\left(\mathrm{S}^{\cap} \mathrm{S}\right)>$ $\mathrm{MeM}\left(\mathrm{S}^{\cap} \mathrm{S}\right)_{2}$. (b) The ${ }^{31} \mathrm{P}\left\{{ }^{1} \mathrm{H}\right\}$ NMR resonances for
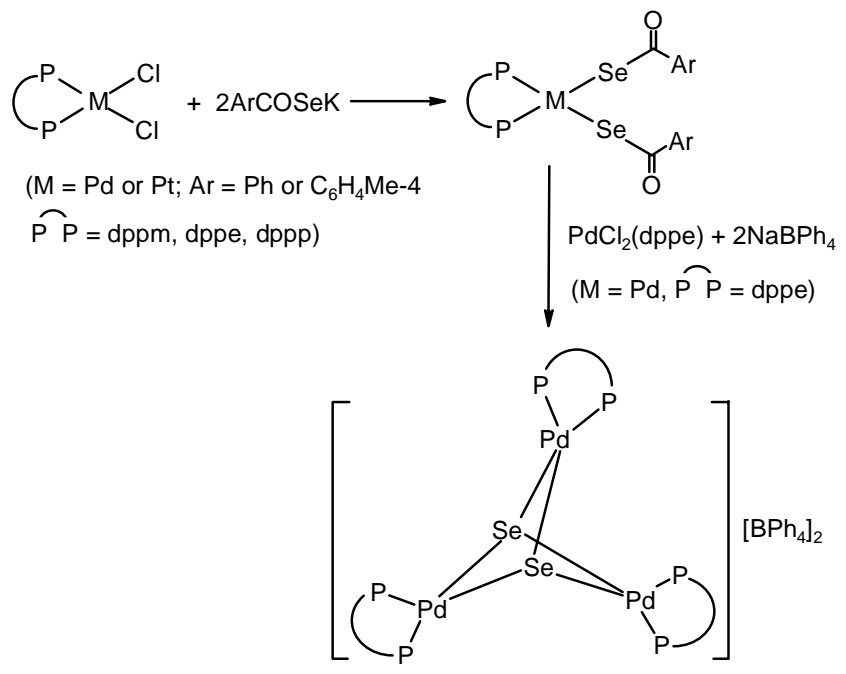

Scheme 4. 


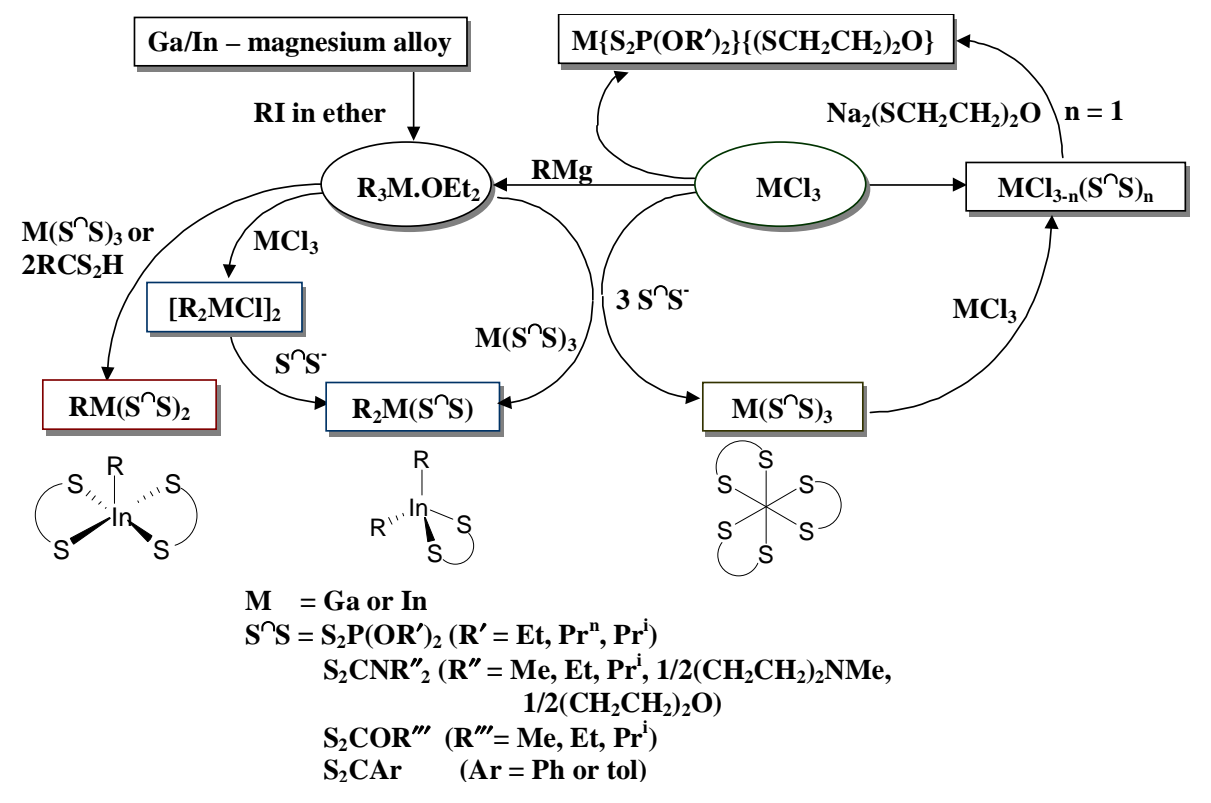

Scheme 5.

dialkyldithiophosphates and $\mathrm{CS}_{2}$ signal in ${ }^{13} \mathrm{C}$ NMR spectra of dithiocarbamates, xanthates and dithiocarboxylates are deshielding with increasing number of dithiolate ligands on the metal and appear in the following order $\mathrm{Me}_{2} \mathrm{M}\left(\mathrm{S}^{\cap} \mathrm{S}\right)<\mathrm{MeM}\left(\mathrm{S}^{\cap} \mathrm{S}\right)_{2}<\mathrm{M}\left(\mathrm{S}^{\cap} \mathrm{S}\right)_{3}$. (c) ${ }^{71} \mathrm{Ga}$ NMR $(I=3 / 2$; natural abundance $39.6 \%)$ spectra of tris dithiocarbamate complexes show a single resonance which is considerably shielded relative to six coordinate hexa-aquo ion. The effects of organic substituents on $\mathrm{R}$ are manifested both on chemical shifts as well as on line widths of the resonances. The observed shifts are interpreted in terms of octahedral configuration.

Structures of a number of complexes have been established unambiguously by X-ray crystallography. The tris complexes have distorted octahedral geometry with all the six M-S distance very similar in each complex. The 2-mercaptoethyl ether complexes are dimeric in which both indium atoms have six coordinate geometry. The 2-mercaptoethyl ether ligand coordinates to indium through both sulphur atoms and oxygen atom, which at the same time bridges the second indium through sulphur. The methyl gallium dithiocarboxylate complex is a monomer but shows distortion isomerism. The gallium atom is five-coordinated acquired by asymmetrically chelated dithiocarboxylate ligands and a methyl group.

Thermal behaviour of several of these complexes has been studied by TG analysis. The organometallic derivatives undergo a two-step decomposition while tris xanthates decompose in a single step. Pyrolysis under different conditions gives different phases. For example, $\left[\mathrm{MeIn}\left(\mathrm{S}_{2} \mathrm{COPr}{ }^{i}\right)_{2}\right]$ at $450^{\circ} \mathrm{C}$ under flowing $\mathrm{N}_{2}$ gave cubic $\beta$ - $\operatorname{In}_{2} \mathrm{~S}_{3}$ whereas under vacuum yielded tetragonal $\beta-\operatorname{In}_{2} S_{3}$.

Thermolyses of indium complexes in solvents were carried out. One representative example is described here. Thermolysis of $\operatorname{In}\left(\mathrm{S}_{2} \mathrm{COEt}\right)_{3}$ in ethylene glycol at $196^{\circ} \mathrm{C}$ gave $\beta$ - $\operatorname{In}_{2} \mathrm{~S}_{3}$ nanoparticles. ${ }^{24}$ The mean particle size of nanoparticles estimated from Debye Scherrer's equation are 13, 19 and $30 \mathrm{~nm}$ for 2, 4 and $6 \mathrm{~h}$ thermolysed samples. XPS indicates the presence of In and S. The core level regions of In $(3 d)$ and $\mathrm{S}(2 p)$ were examined. The indium core is spin-orbit split to $3 d_{5 / 2}$ and $3 d_{3 / 2}$ with peak positions at 444.3 and $452 \mathrm{eV}$ respectively. The $\mathrm{S} 2 p_{3 / 2}$ binding energy of $\operatorname{In}_{2} \mathrm{~S}_{3}$ nanoparticles is centred at around $160 \cdot 8 \mathrm{eV}$. The TEM micrographs show spherical morphology with average size of $30 \mathrm{~nm}$. A corresponding SAED (selected area electron diffraction) pattern confirm the nano crystalline nature. The concentric diffracted rings are indexed outward as (111), (200) and (311) planes corresponding to cubic $\beta$ - $\mathrm{In}_{2} \mathrm{~S}_{3}$. PL spectra provide evidence for quantum confinement of nanoparticles. Under PL excitation at $320 \mathrm{~nm}, \beta-\operatorname{In}_{2} \mathrm{~S}_{3}$ emit blue light at $440 \mathrm{~nm}$ which is highly blue-shifted compared to the bulk material $(620 \mathrm{~nm})$.

Semiconductor nanoparticles of II-VI materials have generated intense research interest due to their 
size dependent optical and electronic properties relative to the bulk materials, making them prospective candidates for a variety of opto-electronic applications and as fluorescent probes in biological imaging. Although several strategies have been adopted for the preparation of II-VI nanoparticles, use of single source precursors has emerged as one of the important synthetic routes offering a fair control on shape and size of the particles. Thus we have synthesized zinc, cadmium and mercury complexes with $\mathrm{N}, \mathrm{N}-$
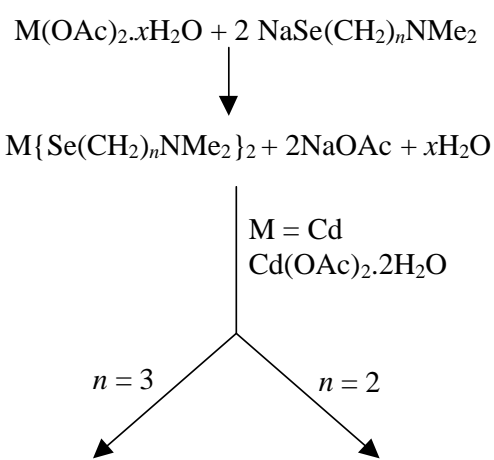

$\left[\mathrm{Cd}(\mathrm{OAc})\left(\mathrm{SeCH}_{2} \mathrm{CH}_{2} \mathrm{CH}_{2} \mathrm{NMe}_{2}\right)\right] \quad\left[\mathrm{Cd}_{3}(\mathrm{OAc})_{2}\left(\mathrm{SeCH}_{2} \mathrm{CH}_{2} \mathrm{NMe}_{2}\right)_{4}\right]$

$(\mathrm{M}=\mathrm{Zn}, \mathrm{Cd}, \mathrm{Hg} ; \mathrm{n}=2$ or 3$)$

$\mathrm{MCl}_{2}$ tmeda $+2 \mathrm{KSeCOAr} \longrightarrow \mathrm{M}(\mathrm{SeCOAr})_{2}($ tmeda $)$

$(\mathrm{M}=\mathrm{Zn}, \mathrm{Cd} ; \quad \mathrm{Ar}=\mathrm{Ph}$ or $p$-tol $)$

( $\mathrm{M}=\mathrm{Hg}, \mathrm{HgSe}$ formed)

Scheme 6.

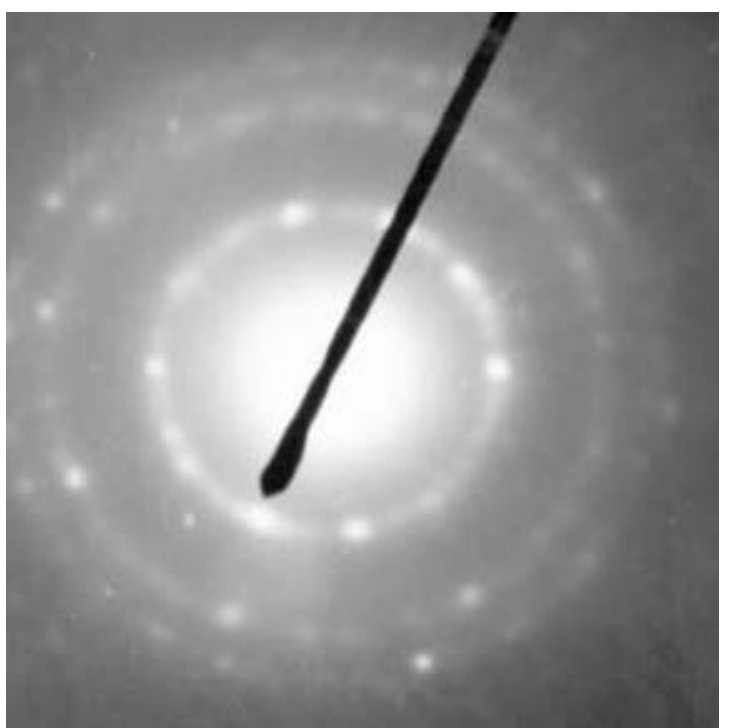

Figure 2. SAED pattern of $\mathrm{HgSe}$ nanoparticles obtained from $\left[\mathrm{Hg}\left(\mathrm{SeCH}_{2} \mathrm{CH}_{2} \mathrm{CH}_{2} \mathrm{NMe}_{2}\right)_{2}\right]$. dimethylaminoalkylchalcogenolate and monoselenocarboxylate (scheme 6) and characterized the products by spectroscopic and X-ray crystallography. ${ }^{26-29}$

The structure of the zinc complex, $\mathrm{Zn}\left(\mathrm{SeCH}_{2}\right.$ $\left.\mathrm{CH}_{2} \mathrm{NMe}_{2}\right)_{2}$ reveal that the coordination geometry around zinc is that of a characteristically distorted "flattened tetrahedron" as is typical for $d^{10}$ centres with two unsymmetrical bidentate ligands. ${ }^{26} \mathrm{TG}$ analysis of $\mathrm{Zn}$ and $\mathrm{Cd}$ complex shows that MSe is formed on pyrolysis, are that the $\mathrm{Zn}$ complex decomposes at higher temperature $\left(260^{\circ} \mathrm{C}\right)$ than that of the $\mathrm{Cd}$ derivative $\left(155^{\circ} \mathrm{C}\right)$. Pyrolysis of cadmium complex was carried out under different conditions. Different sizes and phases are obtained. At lower temperature $\sim 200^{\circ} \mathrm{C}$ a cubic phase is formed.

The molecule, $\left[\mathrm{Cd}_{3}(\mathrm{OAc})_{2}\left(\mathrm{SeCH}_{2} \mathrm{CH}_{2} \mathrm{NMe}\right)_{4}\right]$, has a two-fold rotation axis passing through the central cadmium atom and hence half the molecule forms a crystallographic asymmetric unit. Two terminal cadmium atoms adopt a skewed trapezoidal planar geometry. The coordination around central cadmium is defined by four selenium bridges and adopts a pyrimidalized configuration. ${ }^{28}$

The propylselenolate ligand also affords homoleptic complexes, all of which give metal selenides. Unlike with the ethyl selenolate ligand, the mercury complex could be isolated as a yellow crystalline solid with propylselenolate. The complex is a very useful precursor for the preparation of $\mathrm{HgSe}$ nanoparticles, which are difficult to prepare otherwise. The XRD pattern of $\mathrm{HgSe}$, prepared by different routes, is consistent with a cubic phase and is further confirmed by SAED pattern (figure 2).

The monoselenocarboxylates were also prepared. The ${ }^{77} \mathrm{Se}$ and ${ }^{113} \mathrm{Cd}$ NMR spectra show single resonances. The $\mathrm{X}$-ray structure shows that $\mathrm{Cd}$ has a distorted tetrahedral configuration and has a monodentate selenocarboxylate ligand. The TG shows a three-step decomposition, the first one is the loss of tmeda. Pyrolysis products were analyzed by XRD and EADX. Pyrolysis in HAD gives cubic CdSe nanoparticles. The absorption spectra display a band at $680 \mathrm{~nm}$ which is blue-shifted relative to the bulk CdSe $(713 \mathrm{~nm})$. The mercury complex, unstable at room temperature, also afforded $\mathrm{HgSe}$ nanoparticles.

\section{Conclusions}

We have demonstrated convenient methods to design and develop single-source molecular precursors for binary materials. The chemical aspects of these 
precursors are equally fascinating and interesting. Under different experimental conditions we cannot only control the size of the nanoparticles, but also maneuver the phase of the materials. While we continue to explore precursor chemistry for unitary and binary materials, our future endeavour would be to develop precursors for nanoparticles of ternary systems where properties can be fine-tuned by varying size, phase and composition. Our emphasis will be to develop user-friendly synthetic protocols.

\section{Acknowledgements}

Author expresses his sincere gratitude to his $\mathrm{PhD}$ students, colleagues and collaborators, whose names appear in references, for their immense contributions to this programme.

\section{References}

1. Narayan S, Jain V K and Varghese B 1998 J. Chem. Soc., Dalton Trans. 2359

2. Narayan S, Jain V K, Panneerselvam K, Lu T H and Tung S F 1999 Polyhedron 181253

3. Loknath N K, Devarajegowda H C, Anandalwar S M, Prasad S J, Narayan S and Jain V K 2001 Anal. Sci. (Japan) 17565

4. Dey S, Jain V K, Singh J, Trehan V, Bhasin K K and Varghese B 2003 Eur. J. Inorg. Chem. 744

5. (a) Capdevila M, Clegg W, Gonzalez-Duarte P, Haris B, Mira I, Sola J and Taylor I C 1992 J. Chem. Soc., Dalton Trans. 2817; (b) Marchol S, Moreno V, Aullon G, Alvarez S, Quiros M, Font-Bardia M and Solans X 1999 Polyhedron 18 3675; (c) Real J, Pages M, Polo A, Pinella J F and Alvarez-Larena A $1999 \mathrm{~J}$. Chem. Soc. Chem. Commun. 277

6. Dey S and Jain V K 2004 Platinum Metals Rev. 48 16

7. Dey S, Jain V K, Chaudhury S, Knoedler A, Lissner F and Kaim 2001 J. Chem. Soc., Dalton Trans. 723
8. Dey S, Jain V K, Knoedler A, Kaim W and Zalis S 2001 Eur J. Inorg. Chem. 2965

9. Dey S, Jain V K, Knoedler A, Klein A, Kaim W and Zalis S 2002 Inorg. Chem 412864

10. Dey S, Jain V K, Knoedler A and Kaim W 2003 Indian J. Chem A42 2339

11. Dey S, Jain V K, Knoedler A and Kaim W 2003 Inorg. Chim. Acta 349104

12. Dey S, Jain V K, Klein A and Kaim W 2004 Inorg. Chem. Commun. 7601

13. Dey S, Kumbhare L B, Jain V K, Schurr T, Kaim W, Klein A and Belaj F 2004 Eur. J. Inorg. Chem. 4510

14. Dey S, Jain V K, Varghese B, Schurr T, Niemeyer M, Kaim W and Butcher R J Inorg. Chim. Acta (in press)

15. Kumbhare L B, Jain V K and Varghese B 2006 Inorg. Chim. Acta 359409

16. Kumbhare L B, Jain V K and Butcher R J (unpublished results)

17. Pahari D and Jain V K 1997 Main Group Metal Chem. 20691

18. Pahari D, Jain V K and Patel R P 1998 Main Group Metal Chem. 21261

19. Pahari D, Jain V K and Tiekink E R T 1998 Main Group Metal Chem. 21293

20. Pahari D, Jain V K, Chaudhury S and Tiekink E R T 2001 Main Group Metal Chem. 24405

21. Prasad N, Duta D P and Jain V K 2002 Main Group Metal Chem. 25239

22. Dutta D P, Jain V K, Knoedler A and Kaim W 2002 Polyhedron 21239

23. Ghoshal S, Kushwah N P, Dutta D P and Jain V K 2005 Appl. Organomet. Chem.19 1257

24. Dutta D P, Sharma G, Ghoshal S, Kushwah N P and Jain V K 2006 J. Nanosci. Nanotechnol. 6235

25. Ghoshal S, Dutta D P, Jain V K, Phadnis P P and Nethaji M (unpublished results)

26. Dey S, Jain V K, Chaudhury S, Knoedler A and Kaim W 2003 Polyhedron 22489

27. Kedarnath G, Dey S, Jain V K and Dey G K 2006 J. Nanosci. Nanotechnol. 61031

28. Kedarnath G, Dey S, Jain V K, Dey G K and Varghese B 2006 Polyhedron 252383

29. Kedarnath G, Kumbhare L B, Jain V K, Phadnis P P and Nethaji M 2006 Dalton Trans. 2741 